\title{
Approaching ABET Preparations as a Design Exercise
}

\section{Dr. Wallace T. Fowler P.E., University of Texas, Austin}

Dr. Wallace Fowler has served on the faculty of the Department of Aerospace Engineering and Engineering Mechanics at the University of Texas at Austin since 1965. His early research focused on low thrust interplanetary trajectory optimization. In the 1970s, his research focus broadened to include spacecraft attitude dynamics, tumbling satellite dynamics and retrieval, spacecraft rendezvous and proximity operations, and spacecraft / mission design. His current research centers on spacecraft / mission design and space systems engineering.

Dr. Fowler's has received over a dozen local, regional, and national teaching awards. He is a Fellow of both the ASEE and the AIAA. He is a member of the University of Texas Academyof Distinguished Teachers. He served as President of ASEE in 2000-2001. He was the recipient of the 1985 AIAA/ASEE John Leland Atwood Award and the 1994 ASEE Fred Merryfield Design Education Award. He currently directs the NASA Texas Space Grant Consortium. He has served as an ABET visitor for 24 programs. 


\title{
Approaching ABET Preparations as a Design Exercise
}

\begin{abstract}
Much of the preparation of the self-study for an ABET accreditation visit is collecting and formatting data on faculty, courses, facilities, and equipment. This part of the preparation can be tedious, but it is not open to interpretation by those preparing the document. It is ABET Criterion 4 (Continuous Improvement) that creates the most confusion and most often leads to problems. Criterion 4 requires creation and implementation of processes for assessment of the degree of student attainment of specific Student Outcomes (SOs) and the use of this (and other) information in a continuous improvement of the program. There is often confusion about what data to collect, how to analyze it, and how to present the results in the program's self-study.

The goal of this paper is to provide engineering programs with a workable design-based example of a system that has successfully met the requirements of ABET Criterion 4. The author, an experienced ABET evaluator, developed the system for the aerospace engineering program at the University of Texas at Austin and evolved it during the 2010-2016 ABET cycle. The system resulted in a successful ABET visit in fall 2016 as no program deficiencies or weaknesses were cited by the ABET visitor at the end of the visit. The author's experiences as an ABET evaluator and as a design instructor led to the decision to use design methodology in the satisfaction of Criterion 4.
\end{abstract}

\section{Introduction}

The author was the faculty member responsible for leading his program's ABET preparations during the 2010-2016 ABET cycle. He had been an ABET visitor on 24 occasions. He had seen multiple situations in which massive amounts of extraneous data had been collected in conjunction with Criterion 4 in preparation for an ABET visit. This was usually because those leading the program's efforts did not really understand the accreditation process.

One of the purposes of this paper is to provide guidance on satisfying ABET Criterion 4 through an example process. However, a word of caution is in order. The procedure described here was customized to a particular academic program at a specific university. Be careful if you choose implement features of the procedure for your own program. If something doesn't fit well, change or abandon it.

ABET Criterion 4 - Continuous Improvement (Ref 2)

"The program must regularly use appropriate, documented processes for assessing and evaluating the extent to which the student outcomes are being attained. The results of these evaluations must be systematically utilized as input for the continuous improvement of the program. Other available information may also be used to assist in the continuous improvement of the program." 


\section{Definitions}

ABET Cycle - This is a six year cycle based on the general review ABET accreditation process. In the context of this paper, the ABET general review occurs in the fall semester of year 1 of the general review cycle.

ASE Program Criteria - the Aerospace Engineering Program Criteria published by ABET. These criteria refer to the particular engineering discipline being evaluated.

Assessment Semester - This is a semester in which student work data are collected. For the most recent ABET cycle, we ran a test semester in fall 2012 and collected student work to provide evidence of attainment of Student Outcomes (SOs) in spring 2013 and fall 2014.

Student Outcome (SO) - any of ABET's Student Outcomes (a)-(k). The aerospace engineering program at the University of Texas at Austin has chosen to use ABET Student Outcomes (a)-(k) explicitly.

Targeted Student Outcome - This is a student outcome (SO) that has been chosen for data collection. For most courses, the full set of student outcomes associated with a course will not be targeted for collection of student work during a given Assessment Semester.

Exceptions to this are the writing course, specific laboratories, and the capstone design sequences where student work is used to demonstrate attainment of multiple SOs.

The design process reported here started with the development of preliminary requirements. The formal statement of the need, goals, and objectives were developed iteratively as the process was refined.

\section{Design Need}

An efficient and systematic way to approach satisfying ABET Criterion 4 is needed.

\section{Goals}

(1) Collect and analyze data sufficient for assessment of student outcomes.

(2) Use these analyses plus other data to improve the curriculum.

(3) Avoid collecting extraneous data.

(4) Standardize the data analysis and feedback mechanisms.

(5) Allow the process to evolve (curriculum and/or ABET Criteria change).

(6) Provide clear instructions to faculty members using the system.

\section{Objectives}

(1) Identify, efficiently collect, and analyze data that allows us to clearly assess the degree to which students attain each ABET Student Outcome (SO).

(B) Collect and analyze data that allow us to determine that Student Outcomes (SOs) associated with courses are being targeted by assignments in those courses,

(C) Use information from both (A) and (B) above to improve the curriculum,

(D) Standardize the data analysis and feedback processes. 
(E) Allow the system to evolve in order to make it more efficient, simpler, more responsive, and sustainable.

\section{System Concept}

The system design concept features separate review procedures for student outcome assessment (called the Work Review) and for continuous improvement (called the Assignment Review) process. The Work Review process involves collection of student work, whereas the Assignment Review only involves collection of assignments and solutions. Separation of these review procedures significantly decreases the overall volume of data that must be collected while maintaining or increasing the value of these data.

\section{Work Review (WR)}

ABET student outcomes are achieved at different rates by different students. We need to assess their level of achievement of outcomes at points in the curriculum where the evidence is clear and more easily collectable. We chose to assess student work only in selected upper division (closer to graduation) courses. The courses chosen for this assessment are those in which student work most clearly demonstrates the degree of attainment of various SOs. The courses chosen include laboratories, writing courses, and design courses. In this review, the work of every student submitting an assignment that targets a given student outcome is collected and is reviewed by multiple faculty members to determine the level of student attainment of that outcome. The Work Review data are a superset of the Assignment Review data (assignments plus student work) and Work Review data are used for continuous improvement of these selected courses. The Work Review data are collected in the spring of year 2 and the fall of year 5 of the six year ABET cycle.

\section{Assignment Review (AR)}

Continuous improvement is controlled by instructor. Hence, the Assignment Review process focuses on instructor activities (i.e., design of assignments, tests, etc.), and is the core activity in the continuous improvement process. This review is of the assignments and solutions

only, and not student work. The data sets from Assignment Review are used determine how well instructors are creating assignments that contribute to the attainment of the Student Outcomes associated with their courses. As any given course involves multiple outcomes, usually, multiple assignments are required to demonstrate assignments associated with each outcome associated with that course.

Assignments from every departmentally controlled course in the undergraduate program are examined twice in each 6 year ABET cycle. The schedule for courses only involved in the Assignment Review process calls for data to be collected on four courses each fall and spring semester. This allows 24 courses to be examined every 3 years.

\section{Requirements}

Requirements for the Work Review and Assignment Review processes were developed iteratively over the first three years of the six year ABET Cycle. The final requirements are given below. 


\section{Work Review Process Requirements}

The first sentence of Criterion 4 states: "The program must regularly use appropriate, documented processes for assessing and evaluating the extent to which the student outcomes are being attained." This statement is used as the basis for the following requirements.

1. "The program must shall regularly use appropriate, documented processes for assessing and evaluating the extent to which the student outcomes are being attained." (ABET Criterion 4)

Rationale: This is a modified statement from the ABET's Engineering Program Accreditation Document. The word "must" was replaced by the word "shall" to conform to systems engineering requirements writing standards. The term "regularly" was removed here as it was used to generate the next requirement below.

2. There shall be two occurrences, called Assessment Semesters, during which student outcomes data are collected during each six year ABET cycle.

Rationale: This is done to meet the requirement for regular assessment and evaluation and to provide regular feedback for curriculum improvement in those courses where student work is collected.

3. Where feasible, the system shall assess attainment of Student Outcomes (SOs) in courses near the culmination of the curriculum.

Rationale: The Criterion 4 requirement is to assess the degree to which students are attaining the specified student outcomes. The curriculum is a building block process designed for each student to become more proficient in each SOs as he/she progresses through the curriculum. Hence, it is most appropriate to evaluate the degree of SO attainment as close to graduation as is feasible. This can be done efficiently by selecting, assessing, and evaluating detailed student data from selected courses near the end of the curriculum.

4. The detailed student work collected for assessment of student attainment of each targeted SO shall be evaluated and assessed by the course instructor at the end of the Assessment Semester prior to a second assessment by other program faculty members.

Rationale: Assessment and evaluation of student work by the instructor is a key part of the Work Review process. The instructor has the most information about the assignments, the class, and the student work.

5. At least two faculty members other than the instructor shall evaluate student work targeting each SO to determine the degree to which each student outcome is being attained by the students and provide feedback to course instructors when appropriate.

Rationale: This evaluation is heart of the assessment of student attainment of the SOs and Aerospace Engineering program criteria. These faculty members provide an independent assessment and evaluation of the degree of attainment of each SO and provide feedback for course improvement and curriculum change. This assessment and the resulting feedback to the faculty are essential for curriculum improvement. 


\section{Work Review (WR) Assessment Process}

For the Work Review assessment, the instructor is required to submit copies of the work of all of the students in the class on an assignment that targets the SO selected for the review. After the assignment is graded, the instructor assesses the degree to which the data, in his/her opinion, demonstrate that the targeted SO is being attained by the students in the class. The assignment, the student work, and the instructor's assessment are then reviewed by other members of the faculty who independently assess the degree to which the targeted SO is being attained. The assessment is made on a five point scale. A sixth score (zero) is included in the scale for the situation in which no student work is provided to be assessed. The scale is shown below:

$$
\begin{aligned}
& 5 \sim \text { excellent attainment of the SO by almost all of the students } \\
& 4 \sim \text { satisfactory attainment of the SO by at least } 75 \% \text { of students } \\
& 3 \sim \text { above marginal attainment of the SO by at least } 60 \% \text { of students } \\
& 2 \sim \text { poor attainment of the SO by a majority of students } \\
& 1 \sim \text { little or no attainment of the SO by most of the students } \\
& 0 \sim \text { no student work is provided }
\end{aligned}
$$

The acceptable score for student attainment of each SO is a 4 or better.

The assessments are reviewed and summarized. If a score lower than 4 results from an assessment, the non-instructor faculty members making the assessment write recommendations for improvement. Recommendations for improvement in the course are fed back to the instructor while recommendations for course / curriculum changes are forwarded to the aerospace engineering curriculum committee.

\section{Assignment Review Requirements}

The second sentence of Criterion 4 states: "The results of these evaluations must be systematically utilized as input for the continuous improvement of the program." These requirements pertain to every departmentally-controlled course taught in the aerospace engineering undergraduate program. These courses are called "our courses" in the following paragraphs.

1. There shall be a feedback process, which augments the Work Review process, for continuous improvement of the program.

Rationale: Since we are assessing student attainment of outcomes in courses near the end of the curriculum, we need an additional assessment process for the other courses in the curriculum to provide facilitate continuous improvement. We need to know that instructors in these courses are addressing the student outcomes that are targeted by their courses.

2. Each of our courses not chosen for the Work Review process shall be reviewed on a rotating basis by the Assignment Review process twice in each six year ABET Cycle. Rationale: This review provides two opportunities in each ABET Cycle to determine that each course is targeting its assigned student outcomes. Assignments and student work in courses chosen for the process are subjected to more detailed scrutiny, and hence, 
these courses are excluded from the less extensive Assignment Review process. However, input from the Work Review process is integral to the continuous improvement process.

3. Assignment Reviews shall be conducted during each fall and spring semester on approximately 1/6 of our courses, excluding courses chosen for the Work Reviews.

Rationale: By spreading the AR process over the twelve long semesters of the ABET cycle, the review workload is spread. Also, this provides an ongoing program focus on student outcomes by the faculty. Information from the Work Review reviews will also be used in the continuous improvement process.

4. Faculty members other than the instructor shall assess the appropriateness of assignments targeted student outcomes during semester following the semester in which the Assignment Review data are collected.

Rationale: This process helps to maintain the match of courses and their targeted student outcomes and identifies instances where inappropriate student outcomes have been assigned to a course or assignments are not being made to support appropriate outcomes.

5. Mismatches between assignments and targeted outcomes shall be reported to instructors and to the departmental undergraduate curriculum committee.

Rationale: This feeds information into the appropriate channels for course and curriculum improvement.

\section{Implementation of the Assignments Review (AR) Process:}

Our continuous improvement process uses information from the Work Review process along with the collection and assessment of assignments targeting student outcomes (without student work) from other courses in the curriculum. In this assessment, we check to see that instructors are creating assignments that focused on the student outcomes targeted by their courses. In the 2010-2016 ABET cycle, we did Assignment Reviews, collections in the same assessment semesters that we collected student data for the Work Reviews. This still created confusion among instructors as to what types of data they were to collect. It also created a massive influx of data that had to be processed in a short period of time. A committee of seven faculty members reviewed the assignments. The fact that faculty members are asked to create assignments that target the ABET Student Outcomes associated with their courses seems to stimulate better assignments.

After the fall 2014 semester assessments, we modified the system to collect Assignment Review data every fall and spring, but only on about $1 / 6$ of our courses each semester. We modified the formal requirements for the Assignment Review to reflect this change. These procedures are in effect for our 2016-2022 ABET cycle.

With $1 / 3$ of courses being reviewed each year (1/6 in fall, 1/6 in spring), the match between assignments and targeted SOs are reviewed twice in the ABET accreditation cycle. For the Assignment Review assessment, the instructor is required to submit a copy of an assignment (+ solution) that targets each SO associated with his/her course. It is recommended that, if 
possible, one assignment be designed to target multiple student outcomes. This serves to diminish the volume of data collected for the AR process. As part of the submission, the instructor assesses the effectiveness of the assignment in helping students to attain the targeted SO. The assignment, the solution, and the instructor's assessment are then reviewed by other members of the faculty who assessed the potential effectiveness of the assignment. The Assignment Review assessment is scored on a five point scale. The scale is shown below.

$5 \sim$ the assignment should help almost all students attain the targeted SO.

$4 \sim$ the assignment should help at least $75 \%$ of students attain the targeted SO.

$3 \sim$ the assignment should help up to $60 \%$ of the students attain the targeted SO.

$2 \sim$ the assignment is marginally/poorly related to the targeted SO.

$1 \sim$ the assignment is not related to the targeted SO.

If the score assigned is lower than 4, the reviewer(s) should provide suggestions as to how to improve the assignment to better foster student attainment of the targeted Student Outcome.

\section{Examples of the Results of the Work Review Assessment}

The initial implementation of the Work Review process was in the spring 2013 semester. The table and discussion below show how the results of that SO attainment were reported in the self-study. The courses involved in the table are:

ASE 324L - Aerospace Materials Laboratory

ASE 333T - Engineering Communication

ASE 366K - Spacecraft Dynamics

ASE 367K - Flight Dynamics

ASE 370L - Flight Control Systems

ASE 376K -- Propulsion

ASE 361K - Option A - Aircraft Design I

ASE 361L - Option A - Aircraft Design II

ASE 374K - Option B-Space Systems Engineering Design

ASE 374L - Option B - Spacecraft/Mission Design 


\section{Spring 2013 Work Review Data}

\begin{tabular}{|c|c|c|c|c|c|c|c|c|c|c|c|}
\hline Student Outcome & $\mathrm{a}$ & $\mathrm{b}$ & c & $\mathrm{d}$ & $\mathrm{e}$ & $\mathrm{f}$ & $\mathrm{g}$ & h & $\mathrm{i}$ & $\mathrm{j}$ & $\mathrm{k}$ \\
\hline Course & & & \multicolumn{9}{|c|}{ (Assessment Process was in Development) } \\
\hline ASE $324 \mathrm{~L}$ & NW & NW & & & NW & & NW & & & & NW \\
\hline ASE $333 T$ & & & & & & NW & NW & NW & & NW & \\
\hline ASE $366 \mathrm{~K}$ & 3.5 & & & & & & & & & & \\
\hline ASE $367 \mathrm{~K}$ & 5 & & & & 4 & & & & & & \\
\hline ASE 370L & NW & & & & NW & & & & & & NW \\
\hline ASE 376K & 5 & & & & 4.7 & & & & & & 4.2 \\
\hline \multicolumn{12}{|l|}{ Option A } \\
\hline $\begin{array}{l}\text { ASE 361K, ASE } \\
361 \mathrm{~L}\end{array}$ & 5 & 5 & 4.5 & 5 & 4 & 4.7 & 5 & 4.2 & & 4 & 5 \\
\hline \multicolumn{12}{|l|}{ Option B } \\
\hline ASE 366L & 5 & 3 & & & 5 & & & & & & 4.3 \\
\hline $\begin{array}{l}\text { ASE 374K, ASE } \\
\text { 374L }\end{array}$ & 5 & & 4.7 & 5 & 5 & 4 & 5 & 4.5 & & 4.5 & 5 \\
\hline Attainment OK? & $\begin{array}{l}\text { OK } \\
\text { NW }\end{array}$ & $\begin{aligned} & \mathrm{NO} \\
= & \mathrm{NO}\end{aligned}$ & $\begin{array}{r}\text { OK } \\
\text { WOR }\end{array}$ & & & $\begin{array}{l}\mathrm{OK} \\
\mathrm{D}\end{array}$ & OK & OK & NO & OK & OK \\
\hline
\end{tabular}

\section{Discussion Summary from the Self Study}

Spring 2013 Work Review data indicated that we needed to strengthen our students' attainment on several of the outcomes. The data also indicated that we needed to better instruct our faculty on the amount and types of data needed for the Work Review process. Specific findings included:

Student Outcome (b): Our students' abilities to design experiments were not well demonstrated by the student work and our curriculum gave them little opportunity to demonstrate this ability. This finding resulted in the examination of our laboratory experiences, the dropping of two courses and a laboratory, and the creation of a new required laboratory course (ASE 375 - Electromechanical Systems). 
Student Outcome (f): Demonstration of our students' understanding of professional and ethical responsibility was only being demonstrated in data from the capstone design sequences. The committee felt that the addition of earlier opportunities to measure student understanding of professional and ethical responsibilities would strengthen the program. As a result, this SO became the focus of a change in our Engineering Communications course (ASE 333T) and in exercises in the new laboratory course (ASE 375) created to remedy the shortcoming noted above under Outcome (b).

Student Outcome (i): Evaluation of this student outcome, based on the work of current students, creates an almost impossible task. We currently have no good way to evaluate " $a$ recognition of the need for, and an ability to engage in life-long learning". However, we are advised at ABET briefings not to rely solely on surveys, exit interview data, tracking of graduates, etc. Many of our students go on to graduate schools, go to work for aerospace companies and rise to positions of great responsibility, work for government labs, industry, etc., become MDs, lawyers, work in non-aerospace high tech companies, etc. None of this could happen without life-long learning. Professional success in today's world provides strong evidence of the attainment of this SO, but there is nothing in current student work that provides a good way to measure this. Even a writing assignment that asks students to predict their future educational plans is merely another type of "survey". We found no way to realistically measure this student outcome through current student work in the spring 2013 or the fall 2014 Assessment Semesters.

Student Outcomes (a), (c), (d), (e), (g), (h), (j), (k): Assessment of student data from the spring 2013 Assessment Semester showed an acceptable to excellent student attainment of these outcomes. Note that the scores on SO (f) shown are acceptable, but since some of the requested data were not provided, we chose to ask for additional evidence of attainment of this SO in the next Assessment Semester.

\section{Fall 2014 Assessment Semester Results and System Evolution}

We used the requirements stated above and the results of the fall 2013 assessment semester to improve the Work Review process. In particular, we collected student work for student outcomes assessment from seven courses, five of which are taken by every student. The courses used in the fall 2014 Assessment Semester were:

ASE 324L - Aerospace Materials Laboratory

ASE 333T - Engineering Communication

ASE 375 - Electromechanical Systems

ASE 361K - Option A - Aircraft Design I

ASE 361L - Option A - Aircraft Design II

ASE 374K - Option B - Space Systems Engineering Design

ASE 374L - Option B - Spacecraft/Mission Design

Every student in our program must take the first three courses plus either the Option A or the Option B design sequence. These courses were chosen because they produce student work that involves multiple Student Outcomes that can be readily assessed. The results of the 2014 Work Review assessment are shown below. 
Fall 2014 Work Review Data

\begin{tabular}{|c|c|c|c|c|c|c|c|c|c|c|c|}
\hline Student Outcome & $\mathrm{a}$ & $\mathrm{b}$ & $\mathrm{c}$ & $d$ & $\mathrm{e}$ & f & $\mathrm{g}$ & $\mathrm{h}$ & $\mathrm{i}$ & $\mathrm{j}$ & $\mathrm{k}$ \\
\hline Course & & & & & & & & & & & \\
\hline ASE 324L & 5 & 4.5 & & & 4.8 & & 4.8 & & & & 4.3 \\
\hline ASE 333T & & & & & & 4 & 4 & 4.7 & & 5 & \\
\hline ASE 375 & 5 & 4.7 & & & 4.7 & 5 & 4.3 & & & & 5 \\
\hline \multicolumn{12}{|l|}{$\begin{array}{l}\text { Atmospheric } \\
\text { Design }\end{array}$} \\
\hline $\begin{array}{l}\text { ASE 361K, ASE } \\
361 \mathrm{~L}\end{array}$ & 5 & & 4.7 & 5 & 5 & & 5 & 4.5 & & 4 & 5 \\
\hline \multicolumn{12}{|l|}{ Space Design } \\
\hline $\begin{array}{l}\text { ASE 374K, ASE } \\
\text { 374L }\end{array}$ & 4.2 & & 4.5 & 4.5 & 4.5 & & 4.5 & 4 & & 4 & 4.5 \\
\hline Attainment OK? & OK & OK & OK & OK & OK & OK & OK & OK & No & OK & OK \\
\hline
\end{tabular}

\section{Fall 2014 Work Review Results Summary}

Our fall 2014 Work Review data indicated that we had remedied the problems that we had in spring 2013 with respect to outcomes (b) and (f).

Student Outcome (b): The problem noted in the spring 2013 data with students' abilities to design experiments appear to have been remedied. Experiment design has been strengthened in both ASE 324L (Aerospace Materials Laboratory) and the new laboratory course, ASE 375 (Electromechanical Systems). In ASE 375, students are asked to propose and design an experiment as part of the course. The student reports from this activity are part of the data available to the ABET expert at the time of the accreditation visit.

Student Outcome (f): Additional student work for the assessment of students' understanding of professional and ethical responsibility was collected during the fall 2014 data collection. Work was collected in ASE 333T (Engineering Communication) and in ASE 375. Examination of this work indicated that our students understand ethical and professional responsibility at a level that meets our assessment standards.

Student Outcome (i): We continue to struggle with finding ways to assess students' achievement of this outcome without using exit survey data, student opinions, and alumni survey information. In spring 2016, we obtained the email addresses from the University of Texas ExStudents Association and emailed every student who graduated with the BS in ASE engineering from our program in the interval 2010-2015. We asked the students about their continuing 
education plans and experiences. These data indicated that about $40 \%$ of those responding had sought continued education.

Student Outcomes (a), (c), (d), (e), (g), (h), (j), (k): Assessment of student data from the fall 2014 Assessment Semester continue to show acceptable to excellent student attainment of these outcomes. In the data, it was apparent that we had collected too much student work targeting $\mathrm{SO}$ (a) and $\mathrm{SO}(\mathrm{e})$.

\section{Documentation}

The Work Review and Assignment data collected were collected and placed in notebooks. These notebooks were available for inspection during the ABET accreditation visit. Course notebooks were provided containing course syllabi, course topic schedules, assignments, and student handouts for the most recent semester in which each course was taught. No student work was placed in the course notebooks.

\section{Summary}

An example of a design-based system for collection and documentation of ABET Criterion 4 has been presented. The key features of the system is the careful selection of upper level courses for student work collection and the use of assignment reviews as the primary tool for continuous improvement of the program. The result of implementing these features is a much more efficient and better defined process for dealing with Criterion 4.

\section{References}

1. ABET Engineering Accreditation Criteria 2016-2017

http://www.abet.org/accreditation/accreditation-criteria/criteria-for-accreditingengineering-programs-2016-2017

2. ABET Engineering Accreditation Criteria 2016-2017 - Criterion 4 - Continuous Improvement

http://www.abet.org/accreditation/accreditation-criteria/criteria-for-accreditingengineering-programs-2016-2017/\#improvement 